\title{
CÁLCULO DE RESERVAS HÍDRICAS SUBTERRÂNEAS DO AQUÍFERO RIO CLARO UTILIZANDO SIMULAÇÂO MONTE CARLO
}

\author{
RIO CLARO AQUIFER GROUNDWATER RESERVES ESTIMATE USING MONTE CARLO \\ SIMULATION
}

\author{
Andresa Oliva ${ }^{1}$, Chang Hung Kiang ${ }^{2}$, Wladimir Seixas ${ }^{3}$
}

\begin{abstract}
RESUMO Para calcular a quantidade de água subterrânea existente no Aquífero Rio Claro, no domínio territorial do município de Rio Claro/SP, foi empregada a sondagem elétrica vertical e a simulação Monte Carlo. A sondagem elétrica vertical foi utilizada para calcular o valor médio da espessura saturada do aqüífero que,em geral, é obtida por meio de dados de poços. Mas,no município de Rio Claro são escassos os dados de poços perfurados no Aquífero Rio Claro, dificultando assim, a obtenção de um valor confiável para a espessura saturada. As variáveis "porosidade efetiva" e "variação da profundidade do nível d'água subterrânea" utilizadas no cálculo das reservas permanente e reguladora foram obtidas somente com dados de um único poço;por isso, optou-se pelo uso da simulação Monte Carlo para obtenção destes parâmetros. Com as curvas de distribuição acumulada das reservas permanente e reguladora, elaboradas a partir da simulação, foram gerados cenários para o consumo de água do Aquífero Rio Claro, de grande utilidade para a gestão dos recursos hídricos. Os resultados mostram que a probabilidade do volume da reserva reguladora ser menor que o volume necessário para o abastecimento da população atual do município no período de 1 ano é de apenas $5 \%$.
\end{abstract}

Palavras chave: Aquífero Rio Claro, Simulação Monte Carlo, Reserva Permanente, Reserva Reguladora, Sondagem Elétrica Vertical.

ABSTRACT Vertical Electrical Sounding and Monte Carlo simulation were used with the purpose to establish the amount of groundwater stored in the Rio Claro Aquifer, in the municipality of Rio Claro. The vertical electrical sounding was chosen because one important variable to calculate permanent reserve is average value of saturated thickness of the aquifer. This variable is usually obtained from well data. However, in the municipality of Rio Claro the well data of the Rio Claro Aquifer are scarce, thus making difficult to obtain a reliable value of saturated thickness. Considering that the variables "aquifer area", "specific yield" and "groundwater depth level variation" are also used in the calculation of the permanent and regulating reserves, and because "specific yield" and "groundwater level variation" were obtained only from the wells, the Monte Carlo simulation was chosen to estimate values of permanent and regulating reserves. The cumulative distribution curves of the permanent and regulating reserves, as derived from the simulation, were used to generate some scenarios for the water consumption of the Rio Claro Aquifer, which is of great utility for water resources management . One interesting result of Monte Carlo simulation is that the probabilityof the regulating reserve being lesser than the water demand of the current population of the municipality for a period of one year is of only $5 \%$.

Keywords: Rio Claro Aquifer, Monte Carlo Simulation, Permanent Reserve, Regulating Reserve, Vertical Electrical Sounding.

\section{INTRODUÇ̃̃OO}

As águas subterrâneas têm caráter estratégico em muitas regiões e, em outras, são o único recurso disponível, devido à escassez de água superficial ou até à sua total indisponibilidade.

A maioria dos sistemas de abastecimento público de água,em municípios de grande e médio portes, utiliza água subterrânea, pelo menos de forma complementar. Por isso, as reservas de água subterrânea representam um importante papel na solução de problemas de abastecimento.

A retirada de água subterrânea em quantidades superiores à da reserva reguladora interferena explotação da reserva permanente, que deveria ser considerada estratégica. No entanto, os hidrogeólogos divergem sobre o quanto da reserva permanente pode ser explotada. Os mais conservadores defendem que a reserva reguladora média anual não deve ser totalmente explotada, pois parte dela deverá garantir a vazão dos rios. Já os menos conservadores defendem que a reserva reguladora anual poderá ser totalmen- te explotada, e até um certo percentual da reserva permanente, em casos de extrema escassez.

Aavaliação da reserva permanente de um aquífero sedimentar, particularmente um aquífero livre, envolve muitas discussões, seja pelas metodologias adotadas ou pelos próprios valores encontrados. Dentre essas discussões, um aspecto relevante diz respeito à variável espessura saturada, para a qual, em geral, adota-se um valor médio, representativo do aquífero em toda área explorada. Esse valor é costumeiramente obtido por meio de dados de poços, que muitas vezes não são em grande número ou apresentam descrições litológicas incoerentes de amostras de calha recuperadas durante a perfuração dos mesmos, acarretando imprecisões na determinação da espessura saturada do aquífero.

Esse é o caso do Aquífero Rio Claro, de origem sedimentar, que vem sendo cada vez mais utilizado para o abastecimento industrial e agropecuário, na região do município que lhe emprestou o nome, no estado de São Paulo (Figura 1).

\footnotetext{
$1 \quad$ UNESP - Instituto de Geociências e Ciências Exatas de Rio Claro (aoliva@rc.unesp.br)

2 UNESP - Instituto de Geociências e Ciências Exatas de Rio Claro (chang@rc.unesp.br)

3 Universidade Federal de São Carlos - UFSCar Coordenação Acadêmica de Sorocaba (seixas@ufscar.br)
} 
Devido às dificuldades para o cáculo da reserva permanente desse aquífero, utilizou-se a técnica geofísica de sondagem elétrica vertical, para determinar o valor de sua espessura saturada.

Para minimizar as incertezas na determinação das reservas hídricas, permanente e reguladora,utilizou-se a simulação Monte Carlo. Essa simulação considerados cenários geológicos otimista, pessimista e conservador para as variáveis utilizadas no cálculo de reservas hídricas, para determinar os valores de reservas que, em média, são os mais realistas para esses diferentes cenários.

\section{ÁREA DE ESTUDO}

A área da presente pesquisa compreende cerca de $96 \mathrm{~km}^{2}$ e está localizada no centro-leste do estado de São Paulo (Figura 1), na Depressão Periférica Paulista, unidade geomorfológica com altitudes que variam de 500 a $700 \mathrm{~m}$.

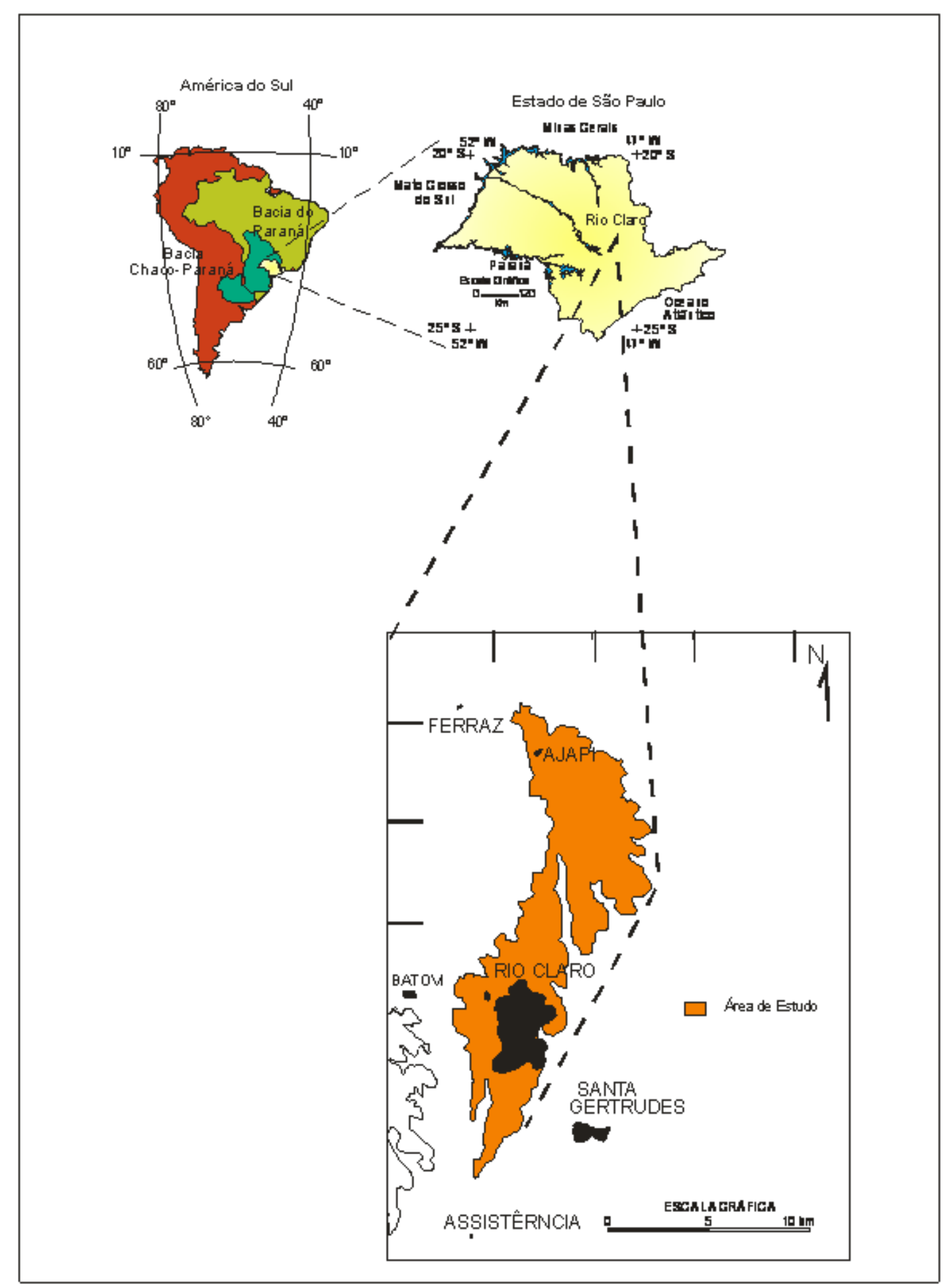

Figura 1. Localização da área de estudo e do município de Rio Claro.

Figure 1. Location of the study area and of Rio Claro County. 
O município de Rio Claro é circundado, em um raio de aproximadamente $30 \mathrm{~km}$, pelos municípios de Corumbataí e Leme, a norte, Piracicaba e Iracemápolis, a sul, Araras e Santa Gertrudes, a leste, Ipeúna e Itirapina, a oeste e inclui os distritos Assistência e Ajapi e os bairros rurais Batovi e Ferraz.

No contexto geológico (Figura 2), a área de estudo localiza-se no setor paulista do flanco nordeste da Bacia Sedimentar do Paraná, onde ocorrem rochas sedimentares e vulcânicas das eras Paleozóica (Subgrupo Itararé, Formações Tatuí, Irati e Corumbataí), Mesozóica (Formações Pirambóia, Botucatu e Serra Geral) e Cenozóica (Formação Rio Claro e depósitos recentes). A área de estudo limita-se à área de exposição da Formação Rio Claro, na região do município homônimo. O Aquífero Rio Claro é sedimentar de caráter livre, constituído por depósitos holocênicos a pleistocênicos da Formação Rio Claro(FERREIRA \& CAETANO CHANG, 2008), que no município homônimo apresenta espessura de aproximadamente $30 \mathrm{~m}$. Nessa

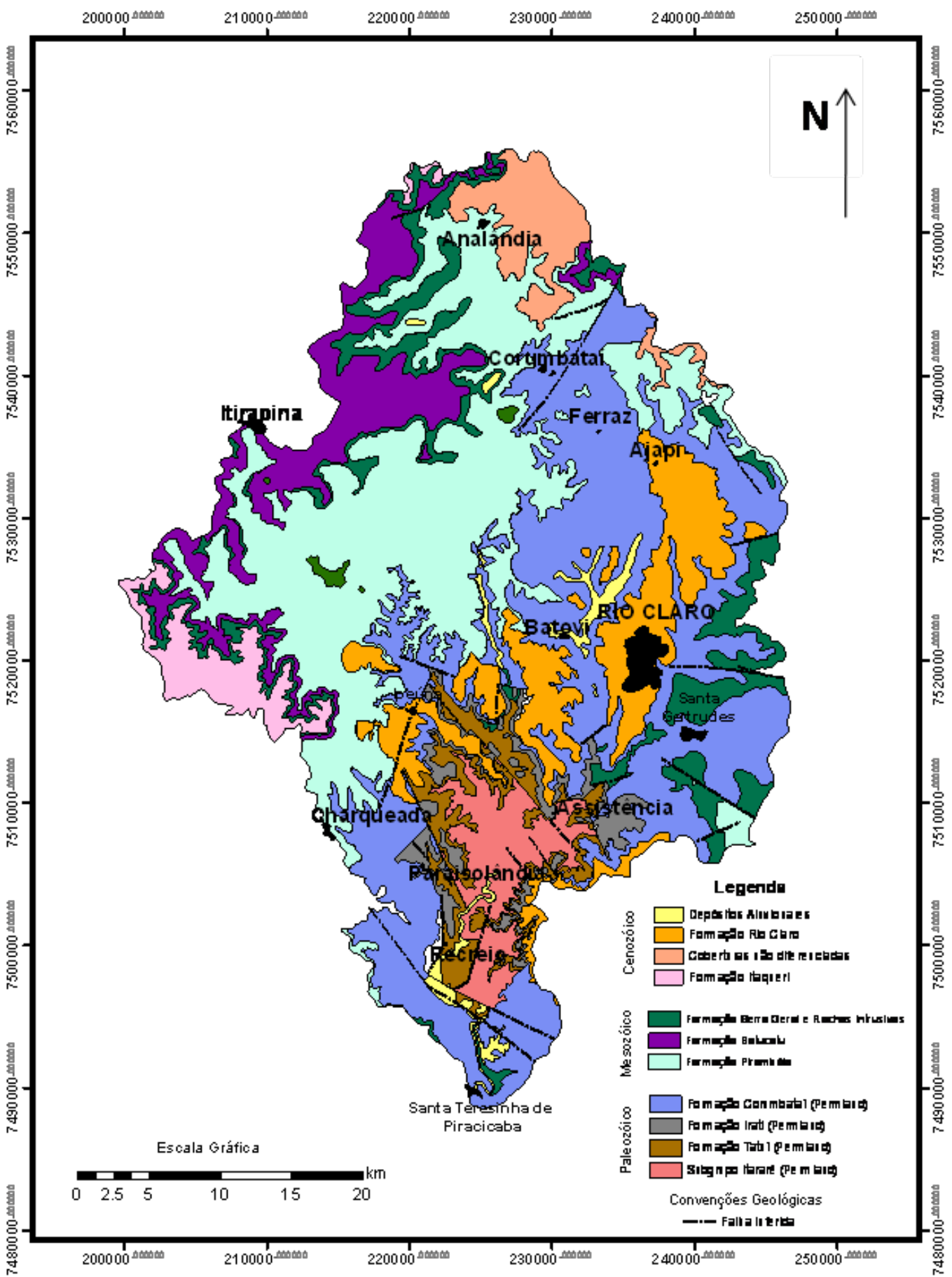

Figura 2. Mapa geológico da bacia hidrográfica do Rio Corumbataí (modificado de CPRM, 1986).

Figure 2. Geologic map of the hydrographic basin of the CorumbataíRiver (modified CPRM, 1986). 
área, os depósitos da unidade ocorrem sobre os sedimentos paleozóicos da Formação Corumbataí; irregularidades topográficas na superfície de contato entre as unidades são responsáveis pelas variações de espessura da Formação Rio Claro.

Segundo Melo et al. (1997), essa unidade possui quatro litofácies principais:a) lamitos de processos gravitacionais, que ocorrem principalmente próximo aos relevos mais acidentados do limite leste da Depressão Periférica, junto ao Planalto Atlântico; correspondem a depósitos texturalmente e mineralogicamente imaturos, muitas vezes sem estratificação, contendo grande proporção de matriz fina e clastos dispersos na matriz lamítica. $\mathrm{Na}$ região do platô de Rio Claro, esses lamitos são sempre delgados e estão situados na base dos sedimentos, correspondendo a paleo-colúvios; b) conglomerados e arenitos conglomeráticos com clastos arredondados de quartzo, com textura variável e estratificação cruzada acanalada e tabular; correspondem a depósitos de fundo de canal fluvial (cascalhos) e barras em pontal (areias), de sistema fluvial meandrante; c) arenitos finos com estratificação planoparalela e cruzada acanalada $\mathrm{e}$, às vezes, laminações cavalgantes, com delgadas intercalações de argila, interpretados como depósitos de rompimento de diques marginais; d) argilitos e siltitos argilosos com estratificação e laminação distinta a indistinta, contendo impressões de folhas e caules, pistas fósseis e deformações de sobrecarga são interpretados como depósitos de transbordamento em planícies de inundação.

Segundo Oliva (2002), os dados obtidos da descrição de amostras, tanto de afloramentos como de poços de monitoramento, juntamente com os de análise granulométrica, indicam que os arenitos da Formação Rio Claro têm granulometria que varia de areia fina à média. Alguns desses arenitos apresentam alto teor de argila e outros são conglomeráticos, indicando que a sedimentação se deu em ambiente fluvial meandrante, no qual os níveis mais argilosos correspondem à planícies de inundação, e os níveis conglomeráticos, aos canais (Figura 3).

\section{METODOLOGIA}

Para a obtenção do valor da reserva permanente, além da variável "espessura saturada" necessita-sedas variáveis "área de ocorrência do aquífero" e "porosidade efetiva".

Para a reserva reguladora utilizou-se o método de Vazão de Escoamento Natural (VEN), calculada a partir das variáveis "porosidade efetiva", "área de ocorrência do aquífero" e "variação do nível d'água subterrânea" (COSTA, 1998).

A variável "área de ocorrência do aquífero" foi delimitada a partir do mapa geológico do município de Rio Claro; as variáveis "variação do nível d'água subterrânea" e "porosidade efetiva" foram obtidas por meio de dados de um único poço, gerando incertezas; a espessura média saturada foi obtida por meio de levantamento geofísico.

\section{Levantamento Geofísico - Sondagem Elétrica Vertical (SEV)}

O levantamento geofísico foi executado utilizando o método de Eletrorresistividade, técnica de SondagemElétrica Vertical(SEV)earranjo Schlumberger. Nos levantamentos de campo foi utilizado o resistivímetro digital da marca SuperSting R8/IP.

O método de Eletrorresistividade consiste na introdução de uma corrente elétrica no subsolo, por meio de eletrodos (designados A e B), e na leitura da diferença de potencial entre dois outros eletrodos (designados $\mathrm{M}$ e N). Considerando a corrente injetada, a diferença de potencial e o fator geométrico K, que depende diretamente das distâncias entre os eletrodos de injeção de corrente e entre os eletrodos responsáveis pela leitura de diferença de potencial, determina-se a resistividade aparente a partir da seguinte equação:

Para aumentar a profundidade de investigação, os eletrodos A e B são afastadospro-

$$
\begin{gathered}
\rho_{\mathrm{a}}=\mathrm{K} \frac{\Delta \mathrm{V}}{\mathrm{I}}, \\
\text { sendo : } \\
\mathrm{K}=2 \pi\left[\left(\frac{1}{\mathrm{AM}}-\frac{1}{\mathrm{BM}}\right)-\left(\frac{1}{\mathrm{AN}}-\frac{1}{\mathrm{BN}}\right)\right]^{-1} \\
\text { onde: }
\end{gathered}
$$

$\rho_{\mathrm{a}}-$ resistividade aparente (ohm.m);

$\mathrm{K}$ - coeficiente geométrico $(\mathrm{m})$;

$\Delta \mathrm{V}$ - diferença de potencial $(\mathrm{V}) ;$

I- corrente (ampères);

$\mathrm{AB}$ - espaçamento entre os eletrodos de emissão de corrente (m);

$\mathrm{MN}$ - espaçamento entre os eletrodos de recepção de potencial (m).

gressivamente e simetricamente ao centro $\mathrm{O}$.

As SEVs utilizaram espaçamento máximo $\mathrm{AB} / 2$ de $100 \mathrm{~m}$, o que permitiu investigar uma profundidade teórica máxima de $30 \mathrm{~m}$. Na prática, esta profundidade depende do contraste entre as resistividades das camadas geoelétricas.

Após a etapa de campo, realizou-se a suavização e a análise qualitativa da morfologia das curvas de campo. Esta análise consta basicamente de um exame visual minucioso das curvas obtidas em campo, possibilitando a separação em grupos e a geração de modelos geoelétricos. 


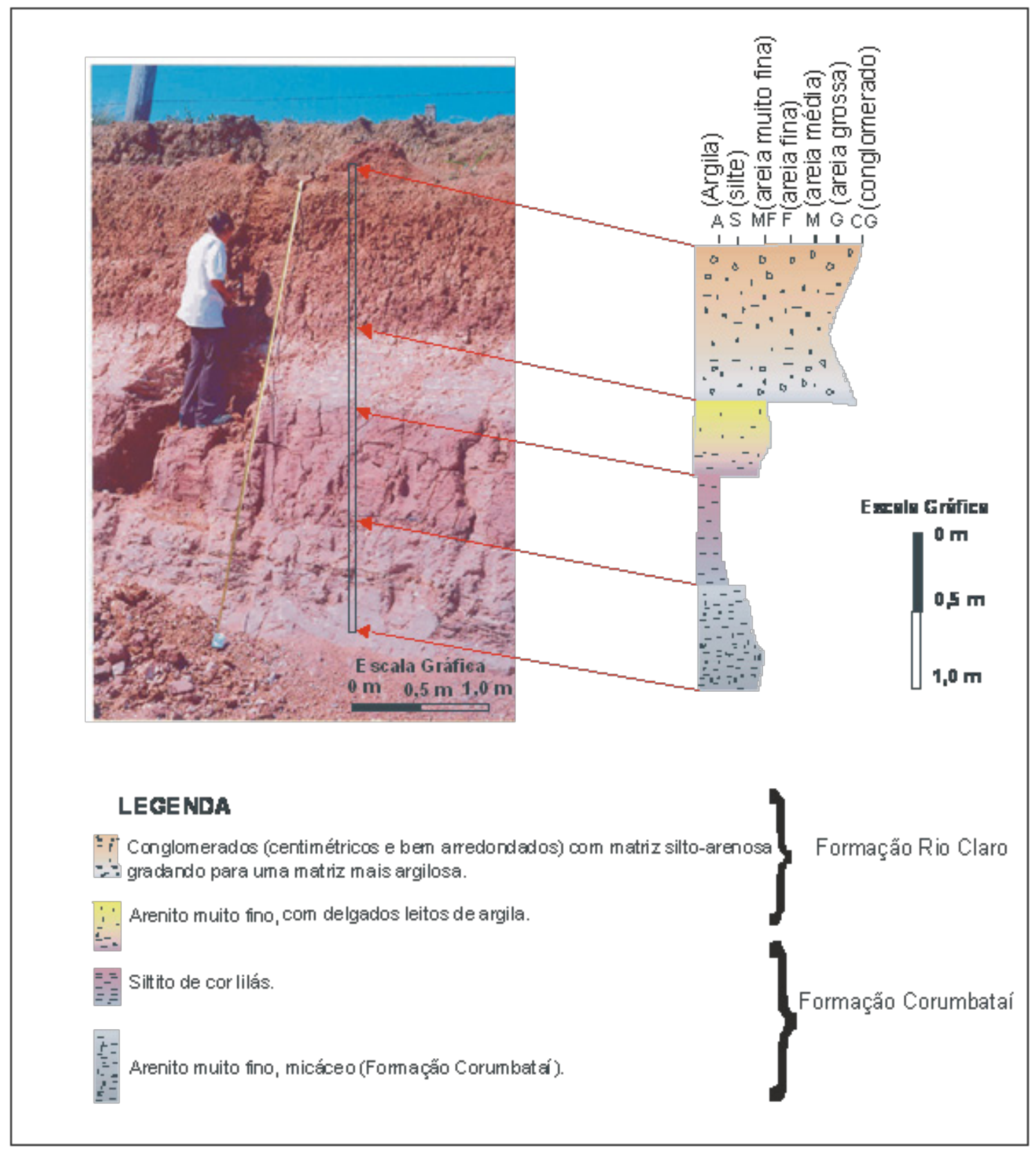

Figura 3. Litofácies da Formação Rio Claro, em afloramento no Km 25, SP 191.

Figure 3. Litofacies of the Rio Claro Formation, in outcrop in Km 25, SP 191.

Os modelos geoelétricos foram refinados pelo software EarthImager 1D, versão 2.0.4, 2006, produzido pela Advanced Geosciences, Inc. (USA), resultando em novos modelos, com a inversão dos dados de resistividade obtidos nos ensaios de campo. $\mathrm{O}$ algoritmo do programa calcula a curva teórica de resistividade aparente, com base na inversão linearizada, conhecida também como método inverso (INMAN, 1975).

Com o intuito de minimizar equivalências na elaboração de um modelo geoelétrico final, foi realizada uma calibração dos ensaios geofísicos. Este procedimento permitiu adicionar e fixar informações durante a inversão dos dados das SEVs, tais como profundidades de camadas com litologias distintas e profundidade do nível $\mathrm{d}^{\prime}$ água. As informações utilizadas na calibração foram adquiridas por meio de (i) descrição detalhada das amostras recuperadas durante a perfuração dos poços de monitoramento na área de estudo, (ii) dados de relatórios de poços de produção perfurados na região e (iii) descrição de afloramentos. Realizada essa calibração, as eletrofácies da Formação Rio Claro foram conferidas e ajustadas, resultando no modelo geoelétrico final.

O levantamento das coordenadas e da altitude das SEVs foi realizado com DGPS (Diferencial Global Position System). Este levantamento utilizou antena e coletor de dados da marca Trimble, modelos PRO-XR12 e TDC1, respectivamente. A 
correção diferencial dos dados obtidos por meio da unidade móvel foi efetuada pelo programa Pathfinder Office, versão 4.0, 2008, utilizando dados base registrados pela antena localizada na UNESP (Universidade Estadual Paulista), em Rio Claro.

\section{Cálculo das Reservas}

A reserva permanente corresponde ao volume de água subterrânea situada na porção saturada, abaixo da posição mínima da variação sazonal do aquífero. Sendo o Aquífero Rio Claro de caráter livre, o cálculo da reserva permanente é dado pelo volume de saturação (Vs), definido por:

$$
\mathrm{V}_{\mathrm{s}}=\mathrm{A} \cdot \mathrm{b} \cdot \eta_{\mathrm{e}}
$$

onde:

A - área de ocorrência do aquífero $\left(\mathrm{m}^{2}\right)$; $\mathrm{b}$ - espessura média saturada do aquífero $(\mathrm{m})$; $\eta_{\mathrm{e}}$ - porosidade efetiva.

O método adotado para o cálculo da reserva reguladora, que corresponde ao volume d'água infiltrado, ou seja, a recarga anual do sistema, foi o de Vazão de Escoamento Natural (VEN). A VEN é calculada a partir da porosidade efetiva, da área de ocorrência do aquífero e da variação do nível d'água subterrânea (COSTA, 1998).

$$
\mathrm{VEN}=\mathrm{A} \cdot \Delta \mathrm{h} \cdot \eta_{\mathrm{e}}
$$

onde:

A - área de ocorrência do aquífero $\left(\mathrm{m}^{2}\right)$;

$\Delta \mathrm{h}$ - variação média do nivel d'água subterrâneo (m);

$\eta_{\mathrm{e}}$ - porosidade efetiva.

A variação do nível d'água subterrânea foi estabelecida por meio de monitoramento contínuo sistemático da coluna d'água em um poço de monitoramento instalado no Aquífero Rio Claro, no Campus da UNESP em Rio Claro, durante quatro anos (2002-2006). A partir desse monitoramento, foi possível obter uma série temporal com significativo nível de detalhe, capaz de registrar pequenas variações, da ordem de $10^{-3} \mathrm{~m}$, associdas a fenômenos naturais (maré terrestre e terremotos).

A porosidade efetiva foi obtida por meio de análises petrofísicas realizadas em amostras recuperadas durante a perfuração do poço utilizado para o monitoramento sistemático de coluna d'água.

\section{Simulação Monte Carlo}

Para diminuir o grau de incerteza no cálculo das reservas permanente e reguladora, aplicou-se o método de simulação Monte Carlo aos dados hidrogeológicos.
Simulação refere-se a qualquer método analítico utilizado pararepresentar algum sistema real, principalmente quando outras análises são matematicamente complexas. Dessa forma, a simulação descreve a distribuição e as características dos possíveis valores de uma variável dependente, depois de determinados os possíveis valores e comportamentos das variáveis independentes a ela relacionadas. Em muitos casos, os modelos de simulação são utilizados para analisar uma decisão envolvendo risco, ou seja, um modelo no qual o comportamento de um ou mais fatores detém alto grau de incerteza. Esses fatores são conhecidos como variáveis aleatórias; seu comportamento é descrito por uma distribuição de probabilidade (MOORE;WEATHERFORD, 2006).

Monte Carlo é um método de simulação que utiliza a geração de números aleatórios para atribuir valores às variáveis que se deseja investigar. Os números podem ser obtidos por algum processo aleatório (tabelas, roleta etc.) ou diretamente do computador, por meio de funções específicas (LUSTOSA;PONTE; DOMINAS, 2004). O número aleatório utilizado em uma rodada não influencia os próximos números aleatórios a serem utilizados.

A qualidade dos resultados obtidos com a simulação depende da escolha da melhor distribuição de probabilidade para cada variável aleatória analisada. Para tanto, é analisada uma sequência de valores para a variável em estudo e, a partir daí, monta-se sua probabilidade de frequência.

Após essa escolha,a variável deverá ser amostrada um número suficientemente grande de vezes, ou seja, será realizado um grande número de iterações. Quanto maior o número de iterações menor será o erro, que pode ser calculado a partir da equação (FERNANDES, 2005):

$$
\varepsilon=\frac{3 \sigma}{\sqrt{\mathrm{N}}}
$$

$$
\begin{aligned}
& \text { onde: } \\
& \varepsilon \text { - erro } \\
& \sigma-\text { desvio padrão da variável aleatória; } \\
& \mathrm{N} \text { - número de iterações. }
\end{aligned}
$$

As variáveis aleatórias e independentes aqui consideradas foram: área, porosidade efetiva, espessura saturada e variação do nível d'água subterrânea; e as variáveis dependentes são as reservas permanente, reguladora e total.

\section{Teste de Normalidade}

O teste foi feito utilizando a técnica gráfica e a 
do valor P. Na técnica gráfica, se a população apresentar uma distribuição normal, os pontos plotados irão constituir uma linha aproximadamente reta. A técnica do valor $\mathrm{P}$, também conhecido como nível de significância da amostra ou observado, que varia de 0 a 1 , determina a conveniência ou não de hipótese nula $\left(\mathrm{H}_{0}\right)$. Quanto menor o valor de $\mathrm{P}$, menor é a consistência entre os dados e a hipótese nula é rejeitada, ou seja, a variável não apresenta uma distribuição normal(MOODet al, 1974).

É necessário, ainda, considerar a probabilidade de se cometer um erro de rejeição da hipótese nula, quando ela é verdadeira; essa probabilidade é simbolizada por alfa $(\alpha)$. Um valor comumente utilizado para este nível de significância é de 0,05 (5\%). Dessa maneira, se o valor de P de um teste estatístico for maior que o nível $\alpha$, a hipótese nula não poderá ser rejeitada.

\section{RESULTADOS E DISCUSSÃO}

Para a obtenção da espessura saturada utilizada no cálculo da reserva permanente foram executadas 134 SEVs (Tabela 1),distribuidas uniformemente em toda área de estudo (Figura 4).

$\mathrm{Na}$ área de estudo, a Formação Rio Claro ocorre predominantemente sobre os sedimentos paleozóicos da Formação Corumbataí. A espessura da Formação Rio Claro foi determinada com precisão pelas SEVs devido ao contraste dos valores de resistividade existente entre as formações Rio Claro e Corumbataí. A Formação Corumbataí é constituída predominantemente por siltitos e lamitos arroxeados, subordinadamente arenitos muito finos, que na área de estudo apresentam valores de resistividades menores ou iguais a $50 \mathrm{ohm} . \mathrm{m}$. Já os valores de resistividade encontrados na Formação Rio Claro saturada, constituída por arenitos finos a médios intercalados por vezes a siltitos argilosos, são menores ou iguais a 500 ohm.m.

A espessura da zona saturada da Formação Rio Claro varia entre $2 \mathrm{~m}$ e $36,3 \mathrm{~m}$, predominando espessuras entre $16 \mathrm{~m}$ e $20 \mathrm{~m}$. As maiores espessuras saturadas localizam-se nas porções norte e central da área de estudo, próximo ao distrito industrial (Figura 5).

Os dados de espessura saturada obtidos nasSEVs passaram por análise estatística para identificar o comportamento da distribuição desta variável (Figura 6). Em seguida, foi realizado o teste de normalidade para certificar-se de quea variável apresenta uma distribuição normal. Para tanto utilizou-se a técnica gráfica e a do valor $\mathrm{P}$.

Para a variável espessura saturada, o valor de P é igual a 0,094 ; portanto, maior que 0,05 , ou seja, a variável apresenta uma distribuição normal.
Esses valores corroboram os resultados da técnica gráfica, conforme pode ser observado na Figura 7.

Após estes testes foi aplicada a simulação MonteCarloàvariávelespessurasaturada(Figura8).

A aplicação da simulação Monte Carlo atribui à variável "área" do Aquífero Rio Claro uma distribuição normal, pois se $\mathrm{n}$ medidas fossem realizadas para medição da área de ocorrência do aquífero estudado, essas $\mathrm{n}$ medidas se repetiriam gerando um erro mínimo e, por conseguinte, um desvio padrão mínimo (Figura 9).

Para a variável porosidade efetiva, obtida de uma única amostra, foi atribuída distribuição triangularpor insuficiência de dados. Para aplicar a simulação Monte Carlo em uma variável nestas condições são necessários trêsvalores: mínimo, máximo e mais provável. O valor mínimo adotado para a porosidade efetiva foi $13 \%$, o máximo foi de $20 \%$ e o mais provável 17,6\%, o da amostra (Figura 10).

Após a simulação Monte Carlo ter sido aplicada a cada variável, foi efetuado o cálculo de reserva permanente, seguida de uma análise estatística. $O$ valor médio esperado foi de 23,213 x $10^{7} \mathrm{~m}^{3}$ (Figura 11).

As mesmas etapas foram adotadas para o cálculo de reserva reguladora. Para asvariáveis "variação do nível d'água subterrânea" e"porosidade efetiva"foi aplicada distribuição triangular na simulação Monte Carlo. $\mathrm{O}$ valor máximo adotado para a variação do nível d'água subterrâneano período entre os anos de 2002 e 2006 (período de monitoramento contínuo) foi $2,80 \mathrm{~m}$ e o valor mí- nimo foi $0,60 \mathrm{~m}$. Como valor mais provável considerou-se a média da variação das medidas que foi 1,75 m (Figura 12). Após asimulação,obteve-se um valor médio esperado de reserva reguladora de $2,462 \times 10^{7} \mathrm{~m}^{3}$ (Figura 13)..

A reserva total obtida pela soma das reservas permanente e reguladora, resultou em um valor médio esperado de 25,675 x $10^{7} \mathrm{~m}^{3}$ (Figura 14).

A partir dos resultados da simulação Monte Carlo foram elaborados gráficos de curva de distribuição acumulada para as reservas permanente e reguladora (Figuras 15 e 16).

Considerando que Rio Claro tem atualmente 192.000 habitantes e que cada habitante em média consome 200 litros de água por dia, em um ano o consumo é de $1,4 \times 10^{7} \mathrm{~m}^{3}$ de água. Se esse volume de água for retirado da reserva reguladora, ou seja, da reserva que pode ser utilizada sem prejuízo do aquífero, existe apenas $5 \%$ de probabilidade de que seja inferior ao necessário para o consumo da população em um ano (Figura 15). Ou seja, o volume necessário dessa reserva 
poderá ser utilizado para o abastecimento da população, no período de 1 ano,de maneira segura.

Se a população duplicar, o volume necessário de água será de $2,8 \times 10^{7} \mathrm{~m}^{3}$,e a probabilidade de que a reserva reguladora seja menor que o volume desejado é de 70\% (Figura 15). Caso essa reserva não comporte o abastecimento da população,a reserva permanente poderá ser utilizada. Nesse caso, $1,4 \times 10^{7} \mathrm{~m}^{3}$,que corresponde ao consumo de água dos192.000 habitantes em 1 ano, seriam retiradosda reserva reguladora, e o volume restante $\left(1,4 \times 10^{7} \mathrm{~m}^{3}\right)$ seriam retirados da reserva permanente, e a probabilidadede que esse volume ultrapasse a reserva é menor que 1\% (Figura 16).
Outro cenário foi simulado:considerando um período de 10 anos, o volume necessário de água para o número de habitantes duplicado será de 28 x $10^{7} \mathrm{~m}^{3}$. Desse volume, $14,0 \times 10^{7} \mathrm{~m}^{3}$ seria retirado da reserva reguladora e os $14,0 \times 10^{7} \mathrm{~m}^{3}$ restantes seriam retirados da reserva permanente. Neste caso, a chance da reserva permanente ser inferior ao volume necessário é de 18,7\% (Figura 16).

O número de iterações para simulação Monte Carlo, calculado por meio da Equação 5, para um erro de $2 \%$ nos valores das reservas, seria de 2.214 . Neste estudo, porém, o número de iterações adotado foi de 300.000 , com um erro de apenas $0,12 \%$ 
Tabela 1. Identificação dos ensaios geofísicos.

Table 1. Identification of the geophysical surveys.

\begin{tabular}{|c|c|c|}
\hline SEV & Leste (km) & Norte $(\mathrm{km})$ \\
\hline SEV-3 & 237,800 & 7522,900 \\
\hline SEV-4 & 236,900 & 7523,600 \\
\hline SEV-5 & 237,300 & 7525,800 \\
\hline SEV-6 & 235,700 & 7522,100 \\
\hline SEV-7 & 235,900 & 7517,300 \\
\hline SEV-8 & 234,800 & 7514,400 \\
\hline SEV-9 & 235,200 & 7514,000 \\
\hline SEV-10 & 236,500 & 7516,800 \\
\hline SEV-11 & 236,700 & 7517,100 \\
\hline SEV-13 & 237,500 & 7525,500 \\
\hline SEV-15 & 237,800 & 7522,100 \\
\hline SEV-16 & 236,300 & 7521,400 \\
\hline SEV-17 & 236,400 & 7522,600 \\
\hline SEV-18 & 237,000 & 7517,300 \\
\hline SEV-19 & 234,300 & 7517,300 \\
\hline SEV-20 & 234,400 & 7519,800 \\
\hline SEV-21 & 233,300 & 7520,100 \\
\hline SEV-22 & 230,500 & 7519,400 \\
\hline SEV-23 & 231,200 & 7519,200 \\
\hline SEV-24 & 230,400 & 7517,000 \\
\hline SEV-25 & 229,700 & 7516,800 \\
\hline SEV-26 & 230,300 & 7516,500 \\
\hline SEV-27 & 230,000 & 7516,000 \\
\hline SEV-28 & 229,900 & 7515,600 \\
\hline SEV-29 & 230,100 & 7515,700 \\
\hline SEV-30 & 231,000 & 7517,300 \\
\hline SEV-31 & 231,400 & 7517,600 \\
\hline SEV-32 & 235,200 & 7519,000 \\
\hline SEV-33 & 237,500 & 7522,600 \\
\hline SEV-34 & 237,000 & 7522,300 \\
\hline SEV-36 & 237,600 & 7526,900 \\
\hline SEV-37 & 237,600 & 7527,200 \\
\hline SEV-38 & 235,800 & 7523,500 \\
\hline SEV-39 & 234,000 & 7522,000 \\
\hline SEV-40 & 234,400 & 7519,200 \\
\hline SEV-41 & 236,200 & 7518,100 \\
\hline SEV-42 & 232,300 & 7523,900 \\
\hline SEV-43 & 231,900 & 7523,900 \\
\hline SEV-44 & 230,100 & 7524,500 \\
\hline SEV-45 & 235,600 & 7523,000 \\
\hline SEV-46 & 239,600 & 7524,600 \\
\hline SEV-47 & 240,300 & 7525,000 \\
\hline SEV-48 & 240,200 & 7524,800 \\
\hline SEV-49 & 240,600 & 7525,100 \\
\hline SEV-50 & 236,900 & 7521,700 \\
\hline SEV-51 & 237,600 & 7521,400 \\
\hline SEV-52 & 234,800 & 7519,800 \\
\hline SEV-53 & 233,390 & 7519,040 \\
\hline SEV-54 & 233,100 & 7520,400 \\
\hline SEV-55 & 233,900 & 7521,000 \\
\hline SEV-56 & 234,400 & 7518,700 \\
\hline SEV-57 & 234,800 & 7517,800 \\
\hline SEV-58 & 235,200 & 7517,200 \\
\hline SEV-59 & 235,900 & 7515,900 \\
\hline SEV-60 & 236,200 & 7515,500 \\
\hline SEV-61 & 236,300 & 7516,100 \\
\hline SEV-62 & 236,200 & 7516,600 \\
\hline SEV-63 & 235,400 & 7517,100 \\
\hline SEV-64 & 235,100 & 7517,500 \\
\hline SEV-65 & 235,000 & 7514,500 \\
\hline SEV-66 & 235,300 & 7515,600 \\
\hline SEV-67 & 235,500 & 7514,500 \\
\hline SEV-68 & 234,100 & 7515,900 \\
\hline SEV-69 & 233,900 & 7514,900 \\
\hline SEV-70 & 236,600 & 7519,800 \\
\hline SEV-71 & 236,400 & 7521,000 \\
\hline SEV-72 & 237,300 & 7521,000 \\
\hline
\end{tabular}

\begin{tabular}{|c|c|c|}
\hline SEV & Leste $(\mathrm{km})$ & Norte (km) \\
\hline SEV-73 & 237,400 & 7519,100 \\
\hline SEV-74 & 237,100 & 7518,900 \\
\hline SEV-75 & 237,200 & 7518,600 \\
\hline SEV-76 & 237,100 & 7520,400 \\
\hline SEV-77 & 240,000 & 7525,900 \\
\hline SEV-78 & 240,000 & 7526,300 \\
\hline SEV-79 & 237,200 & 7519,300 \\
\hline SEV-80 & 239,600 & 7525,900 \\
\hline SEV-81 & 239,500 & 7525,500 \\
\hline SEV-82 & 240,300 & 7525,400 \\
\hline SEV-83 & 239,800 & 7526,700 \\
\hline SEV-84 & 239,200 & 7526,600 \\
\hline SEV-85 & 239,200 & 7526,100 \\
\hline SEV-86 & 239,200 & 7525,100 \\
\hline SEV-87 & 238,100 & 7525,500 \\
\hline SEV-88 & 236,500 & 7518,300 \\
\hline SEV-89 & 234,600 & 7521,100 \\
\hline SEV-90 & 237,700 & 7524,700 \\
\hline SEV-91 & 238,100 & 7524,100 \\
\hline SEV-92 & 237,100 & 7525,600 \\
\hline SEV-93 & 237,500 & 7534,200 \\
\hline SEV-94 & 238,000 & 7534,500 \\
\hline SEV-95 & 237,900 & 7528,400 \\
\hline SEV-96 & 238,000 & 7530,800 \\
\hline SEV-97 & 237,400 & 7532,900 \\
\hline SEV-98 & 237,600 & 7531,100 \\
\hline SEV-99 & 237,600 & 7531,900 \\
\hline SEV-100 & 238,000 & 7529,300 \\
\hline SEV-101 & 236,870 & 7519,150 \\
\hline SEV-102 & 240,739 & 7530,574 \\
\hline SEV-103 & 240,657 & 7531,442 \\
\hline SEV-104 & 240,225 & 7532,485 \\
\hline SEV-105 & 239,458 & 7532,471 \\
\hline SEV-106 & 238,596 & 7532,507 \\
\hline SEV-107 & 239,117 & 7531,962 \\
\hline SEV-108 & 239,589 & 7531,473 \\
\hline SEV-109 & 240,563 & 7530,225 \\
\hline SEV-110 & 241,188 & 7530,313 \\
\hline SEV-111 & 241,558 & 7530,799 \\
\hline SEV-112 & 242,011 & 7530,171 \\
\hline SEV-113 & 241,818 & 7529,823 \\
\hline SEV-114 & 241,330 & 7529,398 \\
\hline SEV-115 & 242,133 & 7529,012 \\
\hline SEV-116 & 239,396 & 7529,485 \\
\hline SEV-117 & 240,017 & 7528,758 \\
\hline SEV-118 & 239,358 & 7527,272 \\
\hline SEV-119 & 241,893 & 7527,826 \\
\hline SEV-120 & 240,974 & 7527,140 \\
\hline$\overline{S E V-121}$ & 241,421 & 7526,938 \\
\hline SEV-122 & 241,249 & 7528,147 \\
\hline SEV-123 & 241,615 & 7527,199 \\
\hline SEV-124 & 240,104 & 7530,295 \\
\hline SEV-125 & 238,388 & 7529,239 \\
\hline SEV-126 & 238,100 & 7532,373 \\
\hline SEV-127 & 238,525 & 7530,970 \\
\hline SEV-128 & 239,071 & 7528,339 \\
\hline SEV-129 & 239,915 & 7527,726 \\
\hline SEV-130 & 242,605 & 7527,637 \\
\hline SEV-131 & 237,861 & 7533,108 \\
\hline SEV-132 & 239,736 & 7533,272 \\
\hline SEV-133 & 237,566 & 7533,708 \\
\hline SEV-134 & 238,055 & 7533,903 \\
\hline SEV-135 & 236,655 & 7535,028 \\
\hline SEV-136 & 238,218 & 7533,109 \\
\hline SEV-137 & 239,056 & 7533,160 \\
\hline SEV-138 & 240,153 & 7533,038 \\
\hline SEV-139 & 240,621 & 7532,976 \\
\hline
\end{tabular}




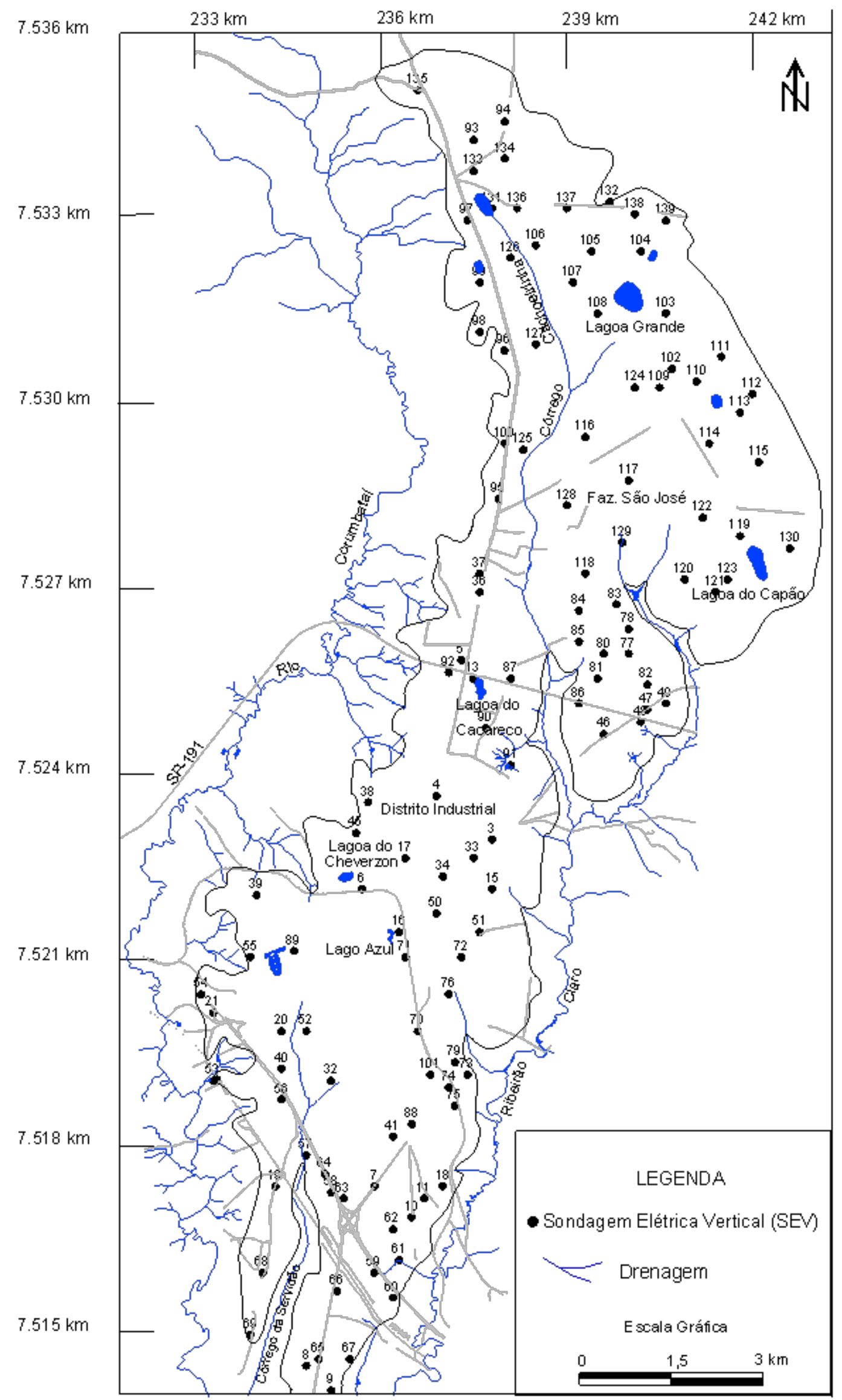

Figura 4. Localização das SEVs na área de estudo. Figure 4. Location of the VESs in the study area. 


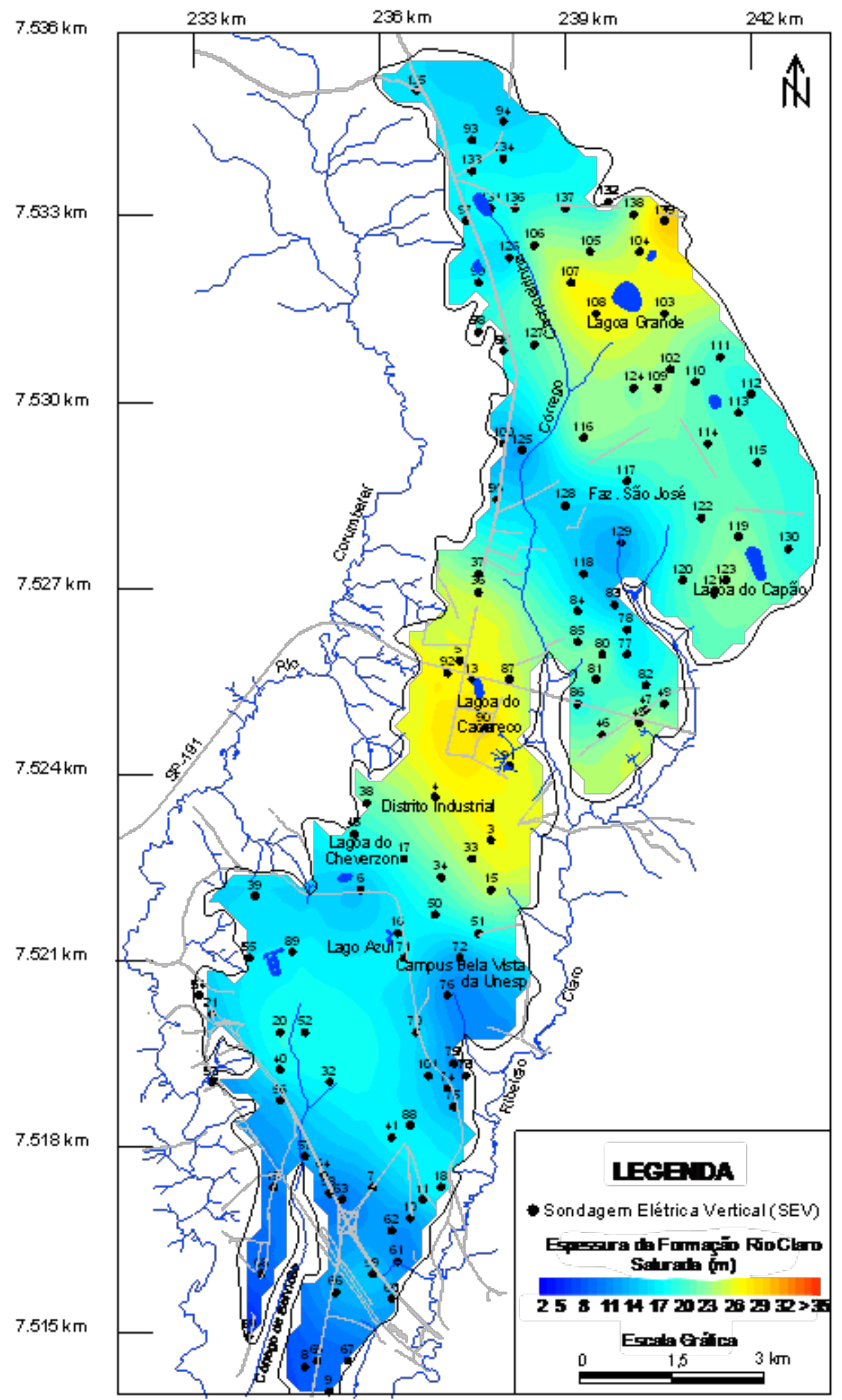

Figura 5. Mapa de iso-espessuras da zona saturada da Formação Rio Claro. Figure 5. Map of iso - thicknesses of the saturated zone of the Rio Claro Formation 


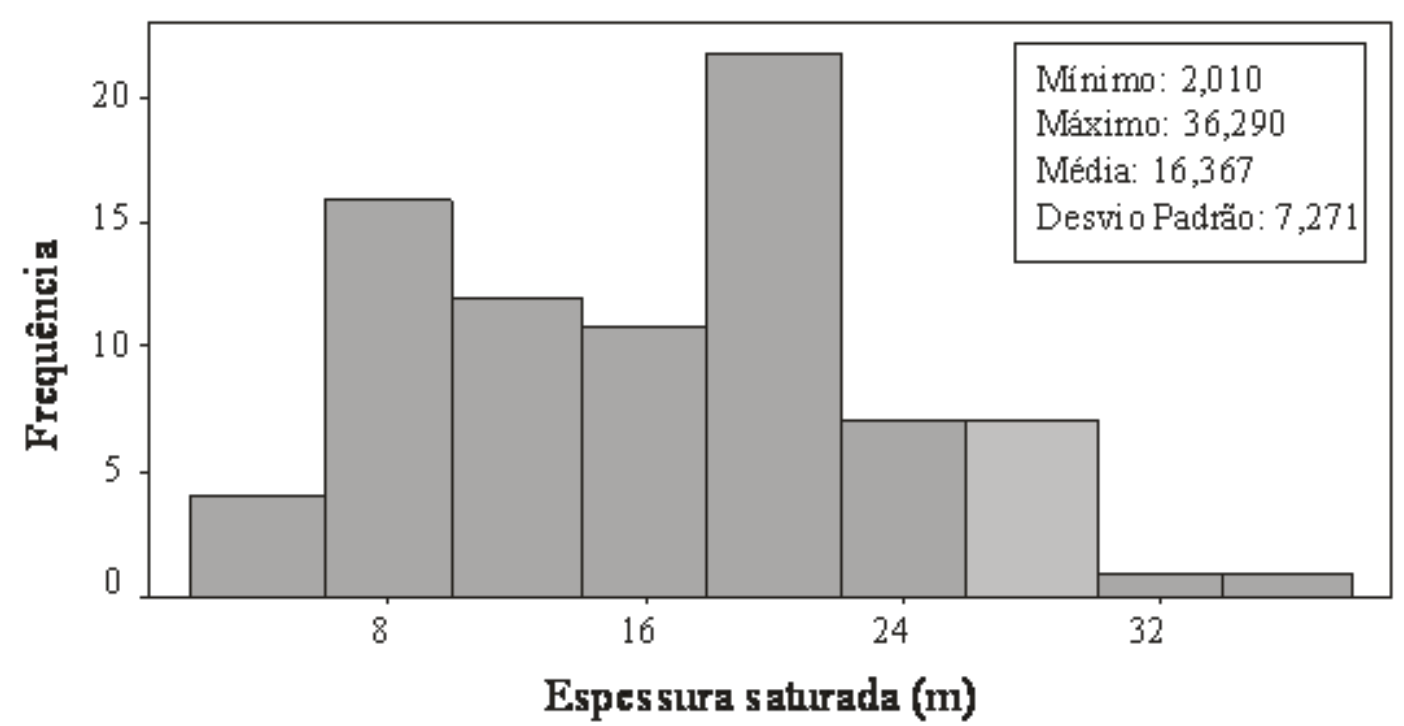

Figura 6. Histograma da variável "espessura saturada" obtida da interpretação das SEVs e sua respectiva estatística básica.

Figure 6. Histogram of the saturated thickness obtained from SEV'S interpretation and its respective basic statistics.

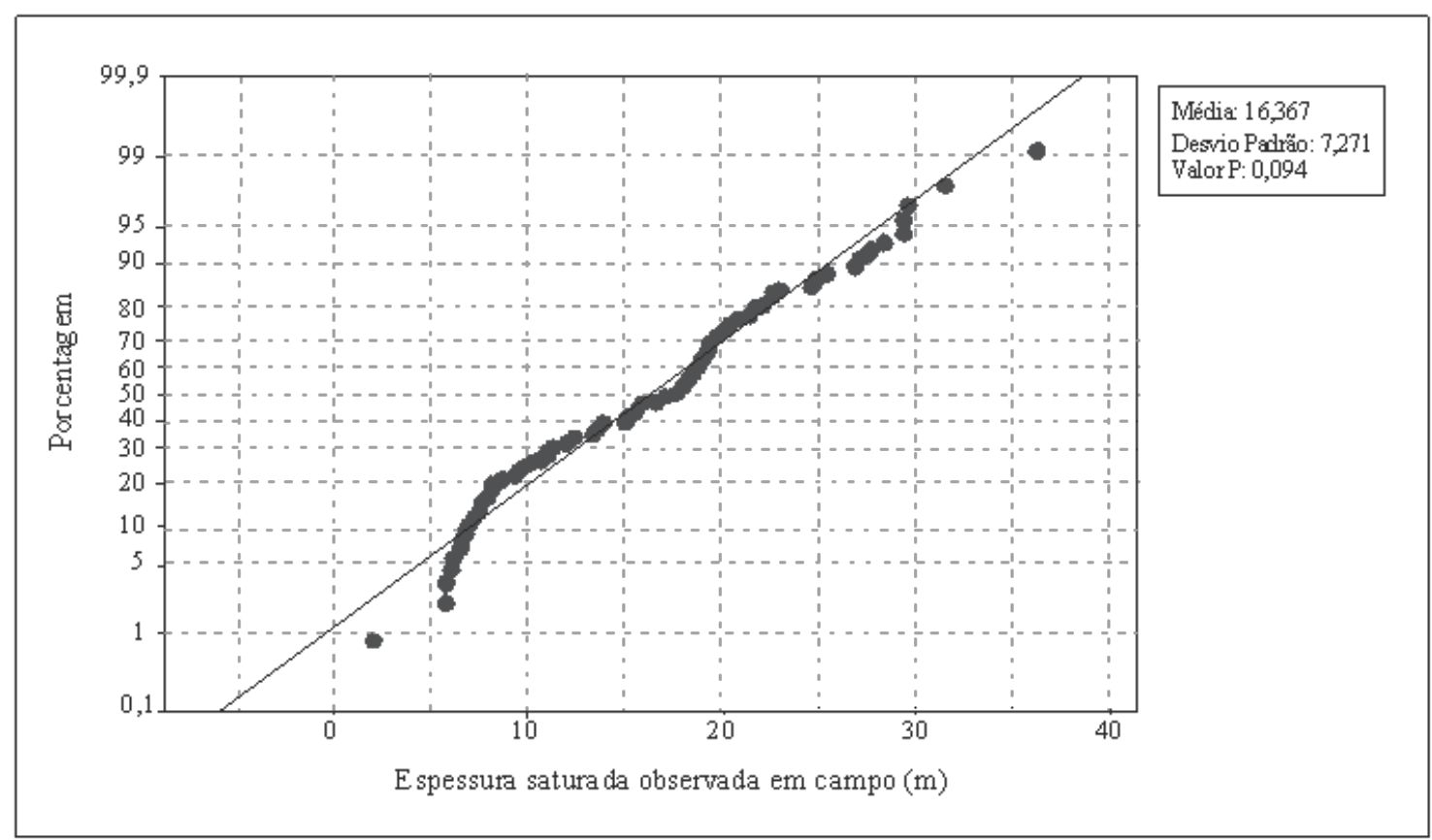

Figura 7. Teste de normalidade para a variável "espessura saturada” obtida da interpretação das SEVs. Figure 7. Normality test to saturated thicknessobtained from SEV'S interpretation 


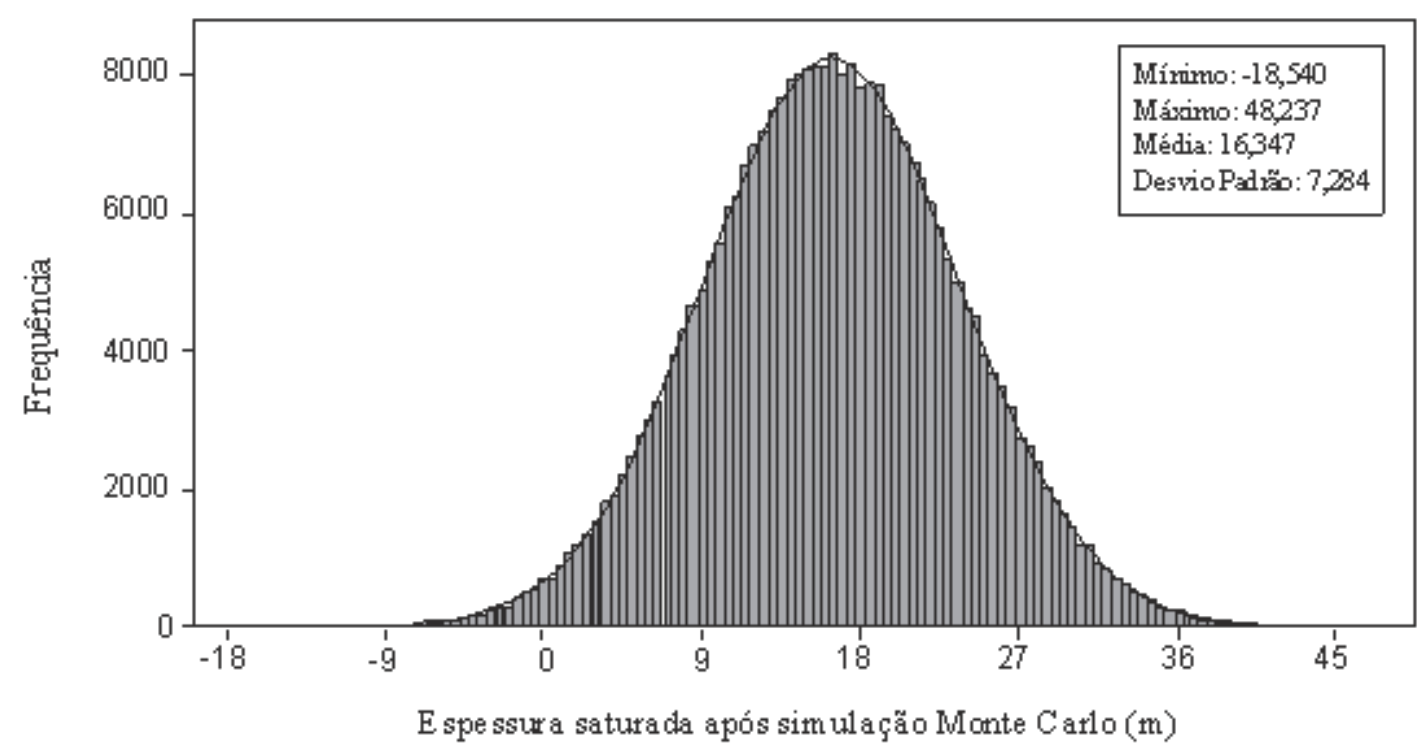

Figura 8. Histograma da variável "espessura saturada" obtido da simulação Monte Carlo e sua respectiva estatística básica.

Figure 8. Histogram of the saturated thickness data after Monte Carlo simulation and its respective basic statistics.

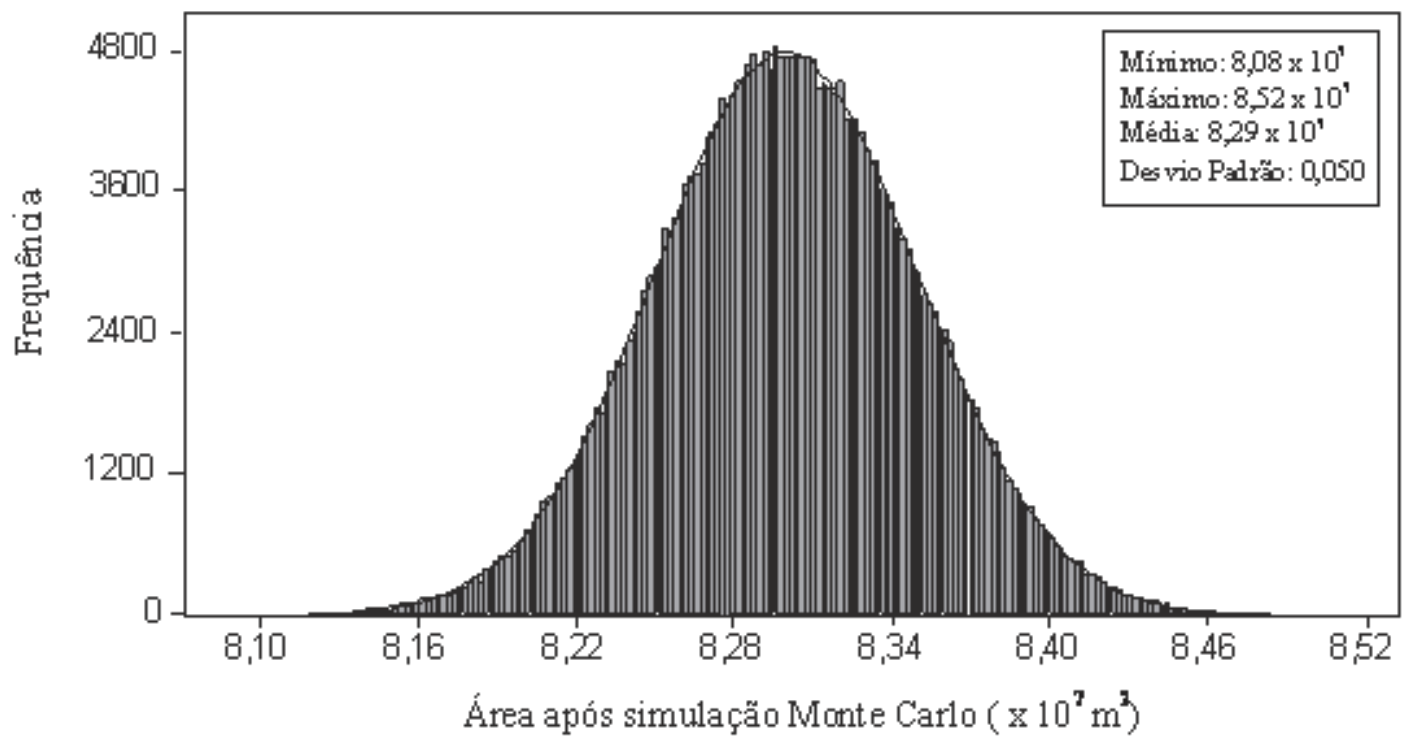

Figura 9. Histograma da variável "área” obtido da simulação Monte Carlo e sua respectiva estatística básica. Figura 9. Histogram of the area after Monte Carlo simulation and its respective basic statistics. 


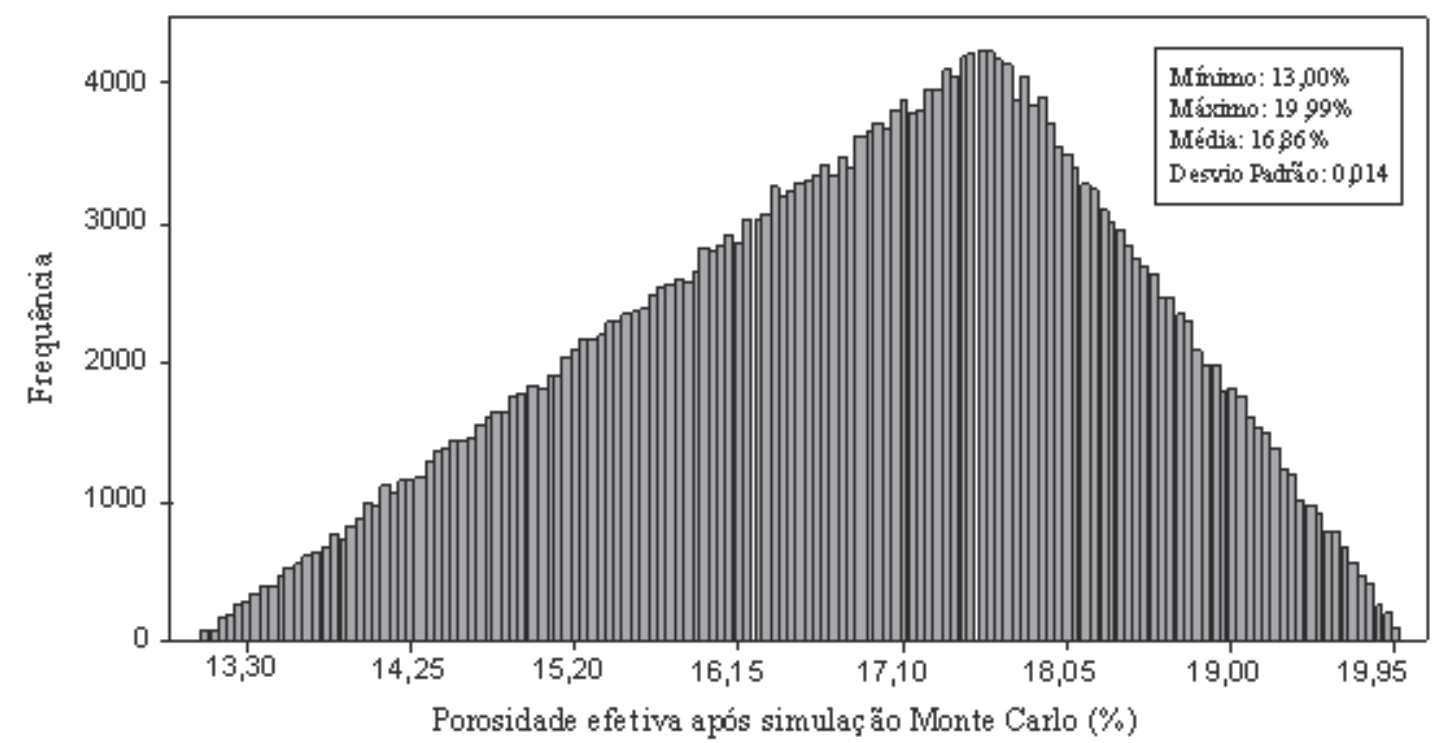

Figura 10. Histograma da variável "porosidade efetiva" obtido dasimulação Monte Carlo e sua respectiva estatística básica.

Figura 10. Histogram of the specific yield after Monte Carlo simulation and its respective basic statistics.

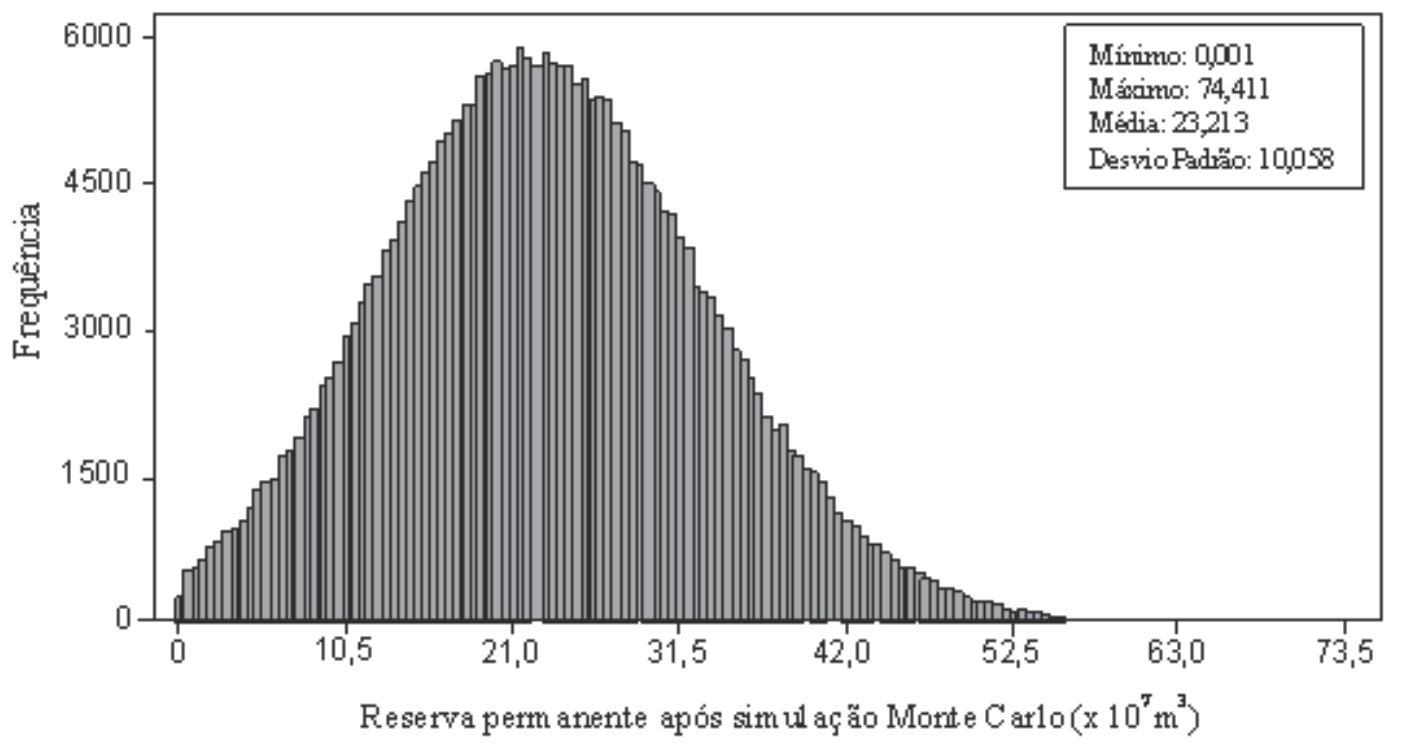

Figura 11. Histograma da reserva permanente obtido dasimulação Monte Carlo e sua respectiva estatística básica. Figura 11. Histogram of the permanent reserve after Monte Carlo simulation and its respective basic statistics. 


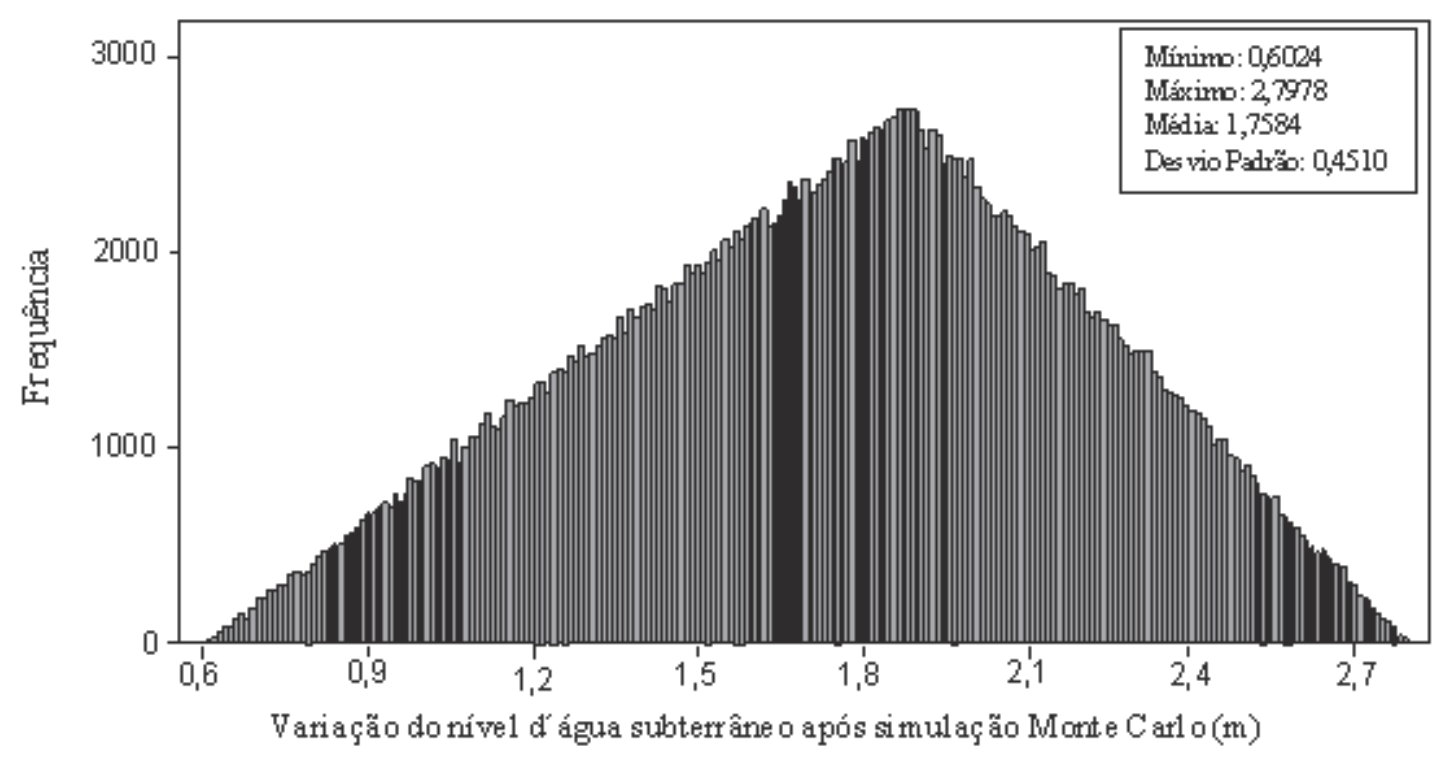

Figura 12. Histograma da variação do nível d'água subterrâneaobtidoda simulação Monte Carlo e sua respectiva estatística básica.

Figure 12. Histogram of the water table variation after Monte Carlo simulation and its respective basic statistics.

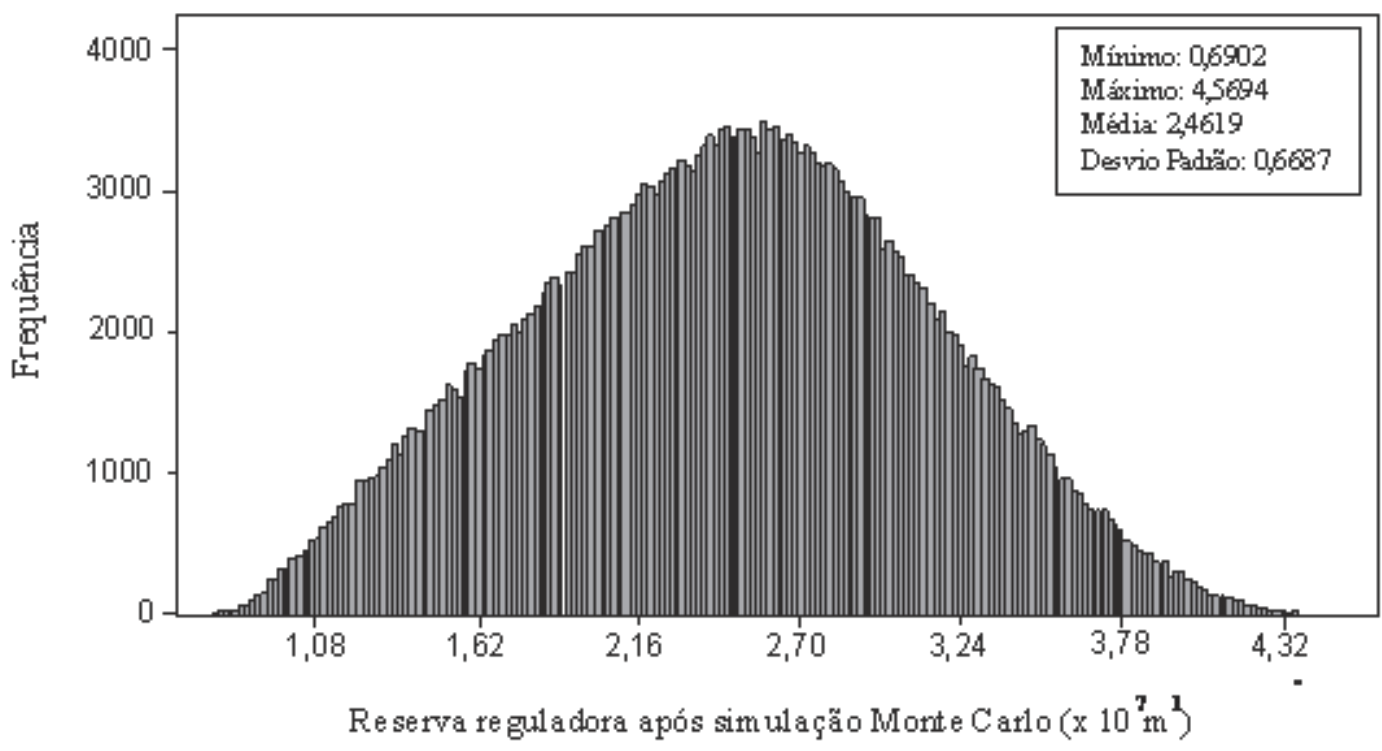

Figura 13. Histograma da reserva reguladora obtido dasimulação Monte Carlo e sua respectiva estatística básica. Figure 13. Histogram of the regulating reserve after Monte Carlo simulation and its respective basic statistics. 


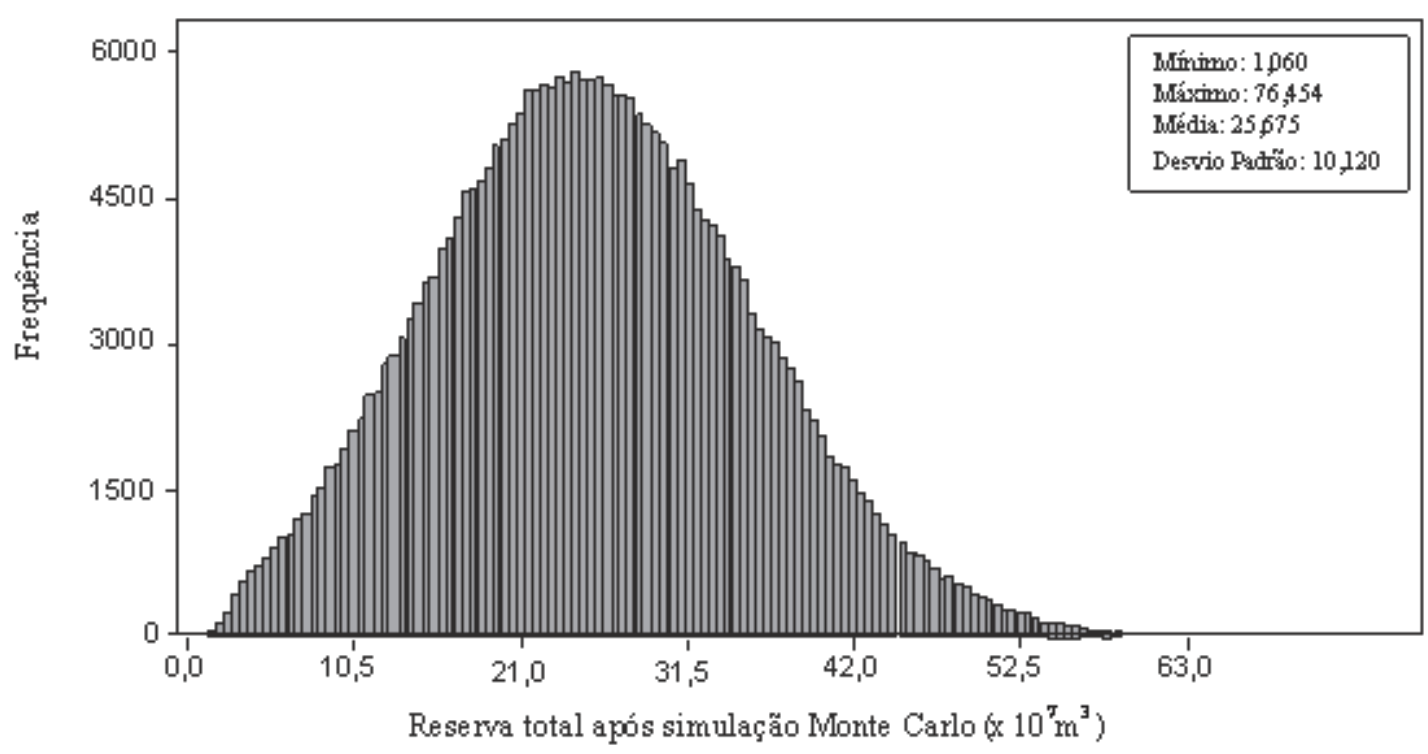

Figura 14. Histograma da reserva total obtido da simulação Monte Carlo e sua respectiva estatística básica. Figure 14. Histogram of the total reserve after Monte Carlo simulation and its respective basic statistics.

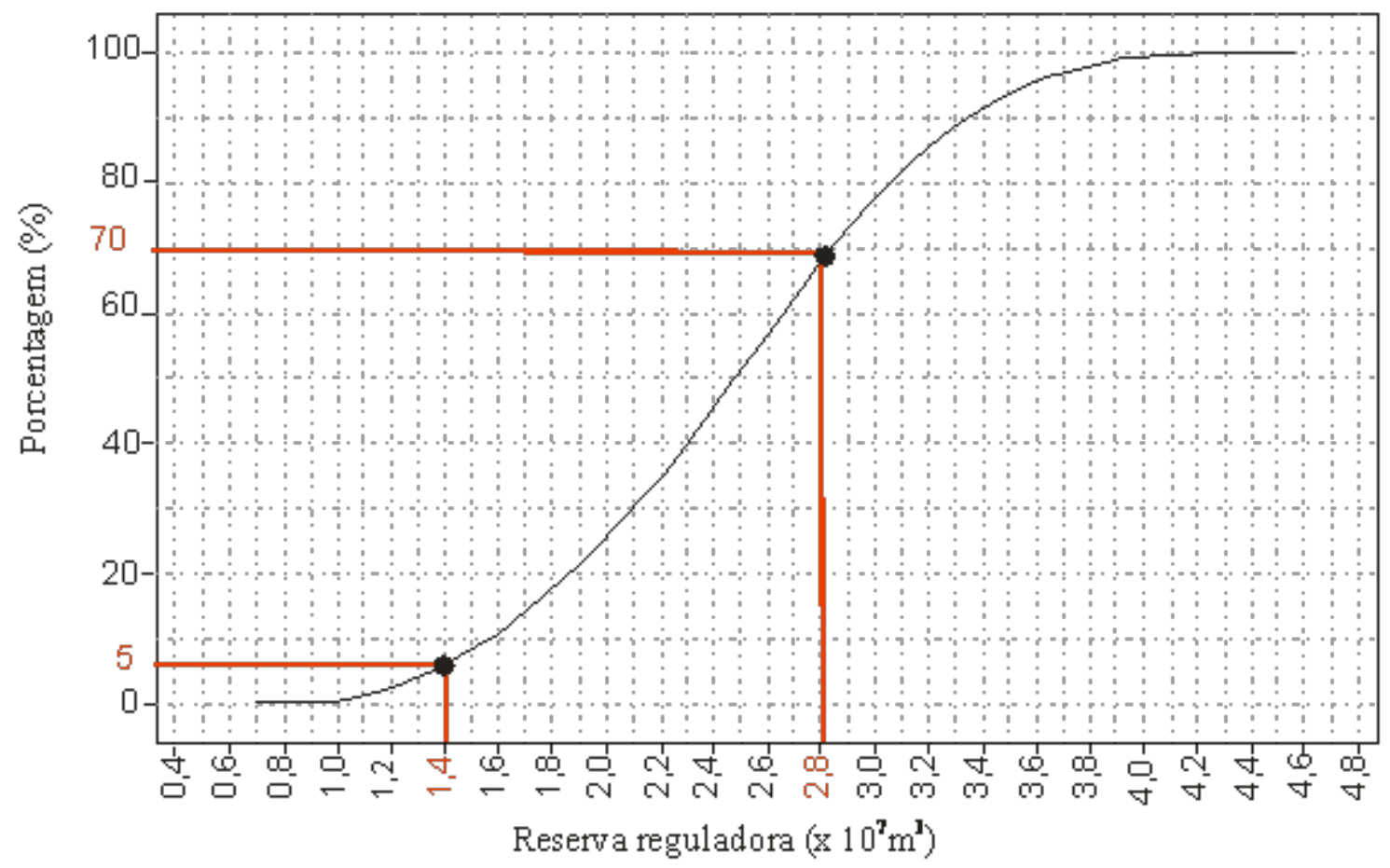

Figura 15. Curva de distrIbuição acumulada da reserva reguladora.

Figura 15. Cumulative distribution curve of the regulating reserve. 


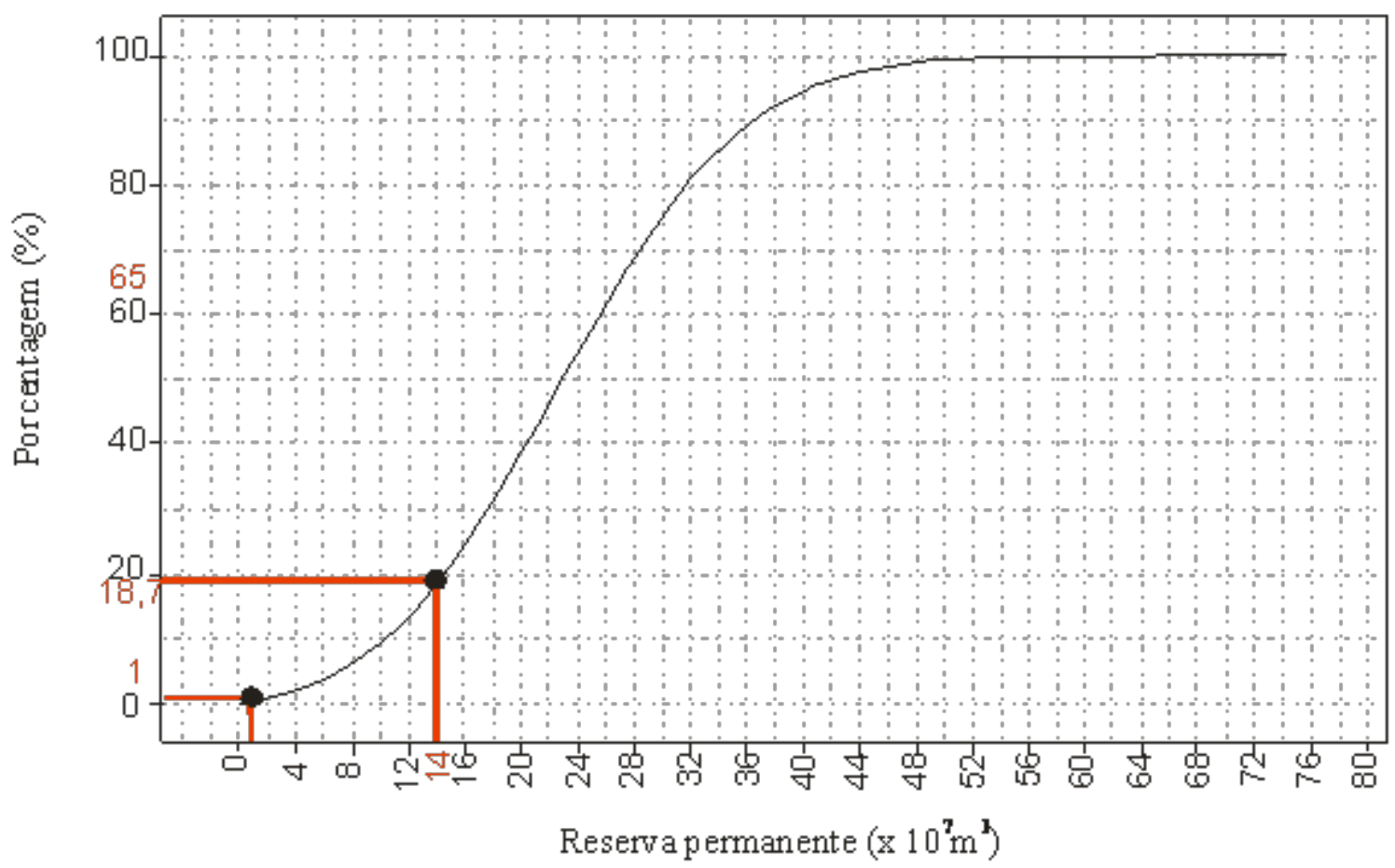

Figura 16. Curva de distribuição acumulada da reserva permanente. Figura 16. Cumulative distribution curve of the permanent reserve.

\section{CONCLUSÕES}

Os resultados obtidos por meio da simulação Monte Carlo aplicada aos dados de levantamento geoelétrico e de monitoramento de poço evidenciam a aplicabilidade desse método para o cálculo de reservas hídricas de um aquífero, mesmo quando os dados disponíveis apresentam incertezas. Nesse caso, a simulação deve usar análise minuciosa da distribuição das variáveis, sob pena de invalidar as estimativas da simulação.

Com os gráficos de distribuição acumulada das reservas permanente e reguladora, elaborados a partir da simulação Monte Carlo, pôde-se gerar cenários para o consumo de água do Aquífero Rio Claro. Um dos cenários mostra que existe apenas $5 \%$ de probabilidade de que a reserva reguladora seja inferior a $1,4 \times 10^{7} \mathrm{~m}^{3}$, que corresponde ao volume necessário para abastecer os 192.000 habitantes do município de Rio Claro no período de 1 ano, seja inferior a $1,4 \times 10^{7} \mathrm{~m}^{3}$, que corresponde ao volume necessário para abastecer os 192.000 habitantes do município de Rio Claro no período de 1 ano, considerando um consumo médio de 200 litros de água por habitante por dia. Os resultados obtidos confirmam a aplicabilidade da metodologia utilizada nesse trabalho em planos de gestão de recursos hídricos subterrâneos.

\section{REFERÊNCIAS BIBLIOGRÁFICAS}

CPRM (COMPANHIA DE PESQUISA DE RECURSOS MINERAIS). 1986.Projeto Borda Leste da Bacia do Paraná: Integração
Geológica e Avaliação Econômica. Relatório Final, São Paulo, SP.

COSTA, W. D. 1998.Avaliação de reservas,potencialidade e disponibilidade de aquíferos. In:X Congresso Brasileiro de Águas Subterrâneas, São Paulo, SP. Anais. Publicação digital.

FERNADES, A. B. A. C. 2005. Como usar o microsoft excel para realizar a simulação Monte Carlo, Gerenciamento de Riscos em Projetos. (www.bbbrothers.com.br/scripts/ Artigos/MonteCarloExcel.pdf).

FERREIRA, S. R.; CAETANO CHANG, M. R. 2008. Datação das Formações Rio Claro e Piraçununga por Termoluminescência. Revista da Escola de Minas, v. 61, p. 129134.

INMAN, R. J. 1975. Resistivity inversion with ridge regression. Geophysics, v. 40, n.5, p. 798-817.

LUSTOSA, P. R. B.; PONTE, V.M. R.; DOMINAS, W. R. 2004. Simulação. In: CORRAR, L. J.; THEÓPHILO, C. R. (Coord.). Pesquisa operacional para decisão em contabilidade e administração: contabilidade e administração: contabilometria. São Paulo, Atlas, p. 242-284.

MELO, S. M.; COIMBRA, M.A.; CUCHIERATO, G. 1997.Fácies Sedimentares da Formação Rio Claro, Neocenozóico da Depressão Periférica Paulista. Revista IG São Paulo, v. 1/2, n. 18, p. 49-63.

MOOD, A. M.; GRAYBILL, F. A.; BOES, D. C. 
1974. Introduction to Theory of Statistics.3. ed. New York: Wiley \& Sons.

MOORE, J. \& WEATHERFORD, L.R. 2006.

Tomada de decisão em administração com planilhas eletrônicas. $6^{\mathbf{a}}$ edição. Porto Alegre: Bookman Companhia Editora.

OLIVA, A. 2002. Estudo hidrogeológico da Formação Rio Claro no município de Rio Claro-SP. 71 p. (Dissertação de Mestrado) -
Instituto de Geociências e Ciências Exatas da Unesp, Campus de Rio Claro, 2002.

\section{AGRADECIMENTOS}

Os autores agradecem ao Laboratório de Estudo de Bacias (LEBAC) - IGCE/Unesp por ceder os equipamentos e acessórios necessários à realização dos ensaios geofísicos. 